Such a group of authors guarantees a lucid and up-to-date exposition of the above mentioned subjects which form the very basis of modern medicine. In the different chapters the work of recent years is analysed and reviewed and woven into a logical story of the present state of our knowledge with its implication in the study, understanding and treatment of disease.

The book is well produced. The type is clear and pleasing. The text is profusely illustrated with charts and diagrams and pictures (355 in all), and there is a liberal bibliography which is well up-to-date as well as a full and ample index.

\section{THE CONSTRUCTION OF VULCANITE APPLICATORS FOR APPLYING RADIUM TO LESIONS OF THE BUCCAL CAVITY, LIPS ORBIT AND ANTRUM.}

By Desmond Greer WALKer, M.A., M.Dent.Sc., M.B., B.Ch. Foreword by W. WARWICK JAMES, O.B.E., F.R.C.S., L.D.S. John Murray, London. Illustrated with twenty-three plates. Pp. 61. 1938. Price 5s.

The Construction of Vulcanite Applicators for applying Radium to lesions of the Buccal Cavity, Lips, Orbit and Antrum, by Desmond Greer Walker, M.A., M.Dent. Sc., M.B., B.Ch., should prove of great value to radium workers.

It deals concisely with the main physical points in the use of vulcanite applicators and gives full information regarding their construction.

The methods of obtaining impressions and the choice of material is fully discussed and a new method is given in full detail.

The construction of applicators for special cases, and the means of fixation are described in detail.

The book is illustrated by many photographs which are all of good quality.

There is a short list of references.

\section{PRACTICAL PROCEDURES.}

Vol. Ir. of the Practitioner Handbooks.

Edited by Sir Humphry Rolleston, Bt.,

and Dr. Alan MoncriefF. Eyre and

Spottiswoode, Ltd. 1938. Price 10/6.

This volume consists of reprints of a series of articles on every-day practical procedures in medical practice which were specially written for "The Practitioner" and in which journal they have already appeared. The choice of subjects has been particularly happy as most of the procedures dealt with are liable to be required in daily practice. Some of the procedures are emergency measures, e.g., saline transfusion, blood transfusion, lumbar puncture, thoracocentesis, local anæsthesia and the treatment of poisoning. Thus it is good that the practitioner may have at hand for ready reference practical accounts of the most suitable technique. Other chapters deal with equally important although less urgent therapeutic and diagnostic aids, as e.g., the use of plaster splints, the injection of veins, circumcision, syringing of the ears and the examination of the blood and urine. The format of the book is pleasing, it is light to handle, the type is clear, the diagrams are unusually intelligible and there is a very full index which eminently fits the book for the purpose for which it has been designed.

\section{A TEXTBOOK OF CLINICAL PATHOLOGY.}

Edited by RoY R. KRACKE. Emory Univerșity, Ga. Baillière, Tindall \& Cox. London. Pp. 574. 205 illustrations. 31 plates, 19 in colour. 1938. Price 27/-.

Most physicians appreciate the importance of laboratory work in practical medicine, but find some difficulty in keeping in touch with recent developments and with modern ideas on its scope and limitations. Dr. Kracke has produced a. Textbook of Clinical Pathology which helps considerably; lucid, readable, beautifully illustrated, it is written by twelve authorities on the subject for students of medicine and practising physicians.

This is a book which gives just the information a practitioner needs. It is not a book of laboratory technique. Technical details are given, but the authors have wisely confined themselves, as a rule, to one - method only for each investigation; a method chosen for its reliability and simplicity. So much is vital for a complete understanding of the subject.

These accounts of laboratory technique are clear and interesting - an effect achieved in part by numerous excellent illustrations. Students and junior clinical pathologists particularly will find them most valuable; from their point of view there can be no 